Journal of the Scholarship of Teaching and Learning, Vol. 21, No. 3, October 2021, pp. 98-102.

doi: 10.14434/josotl.v21i3.29896

\title{
A Method for Directing Collaborative Study Guide Construction by Undergraduate Student Groups
}

\author{
Maureen L. Petrunich-Rutherford \\ Indiana University Northwest \\ mlpetrun@iun.edu
}

\begin{abstract}
Students often request study guides; however, the impact of study guides on student learning is mixed. Here, some evidence on student study guide usage and collaborative learning is briefly reviewed. This information helped to shape the development of a collaborative activity where student groups create their own study guide questions based on the chapter learning outcomes. Requiring students to collaborate and create their own study guides may encourage a higher engagement with and deeper processing of the course content.
\end{abstract}

Keywords: study guides; team-based learning; collaboration; undergraduate

\section{The Effect of Study Guides on Student Learning is Nuanced}

Although students often request study guides from instructors, the utility of these pedagogical support tools remains under question. Study guides are ultimately designed to help students focus on the key concepts of the material being learned and encourage students to develop specific skills (Wood, 1989); however, students can focus on the material covered by a study guide exclusively and neglect material not covered by the study guide (Lloyd \& Eastman, 1977). Hence, study guides have been shown to be useful in some, but not all, contexts. It is critical that the nuances of study guide design be considered so that the study guide has a desirable impact on student learning.

There are many study guide frameworks that instructors can utilize, such as providing example multiple-choice questions (Dickson et al., 2006), reading guides (Polson, 1995; Wood et al., 1992), computer-based packages (Mooney et al., 1995), or lists of important concepts (Cushen et al., 2019). The effectiveness of study guide type may depend on how much the activities contained on the study guide align with the targeted content knowledge or skill and how the concepts and skills are being assessed. If the study guide exercises engage students in equivalent or more effortful processing of the material, students should perform well on the assessment (Dickson et al., 2006). However, if the study guide exercises rely on memorization of the course material (e.g., matching key terms to definitions), but the assessment requires applicational understanding of the course content (e.g., essay questions), the study guide may not encourage effective student learning. Thus, instructors desiring to utilize or distribute study guides should carefully map study guide activities to learning outcome assessments when designing effective study guides for their classes.

Students generally perceive study guides as helpful; this perception of usefulness correlates to student's use of these tools as pedagogical aids (Gurung, 2003). Instructors should not rely on student perceptions of helpfulness for study guide usefulness, however, as perceived helpfulness and use of study guides do not necessarily relate to exam performance (Gurung, 2003, 2004). For example, the perceived helpfulness of certain types of items on a study guide, such as using key terms provided by the textbook, was inversely correlated with exam performance (Gurung, 2003). In addition, although students vastly prefer instructor-provided study guides, an instructor-provided concept-list study guide negatively impacted student learning compared to when students were not given a study guide and were instead encouraged (but not required) to create study guides on their own (Cushen et al., 
2019). Students required to complete a study guide had higher exam scores compared to students that had access to study guides, but were not required to use the study guides to prepare for the exam (Dickson et al., 2005).

Thus, if instructors desire to use study guides, the guide should be crafted to engage students with the material at a higher or equivalent level of processing as the assessment. In addition, requiring the construction of a study guide (rather than just using an instructor-provided study guide) may encourage students to actively engage with the material, which is generally associated with positive student learning outcomes (Chi \& Wylie, 2014; Prince, 2004).

\section{Collaborative Learning}

Student collaborations are associated with gains in a variety of student learning outcomes. For example, a meta-analysis found that small group learning in undergraduate courses was positively associated with academic achievement and students' perceptions of learning (Springer et al., 1999). Student collaborations on exam reviews (Drouin, 2010), group worksheets and assignments (Delucchi, 2007; Gokhale, 2012), "jigsaw" activities (Perkins \& Saris, 2001; Smith et al., 1991), and quizzes (Petrunich-Rutherford \& Daniel, 2019) were all associated with a variety of positive learning outcomes, such as higher exam or quiz scores, by students engaging in collaborative learning exercises. In fact, collaborative learning strategies had one of the highest effect sizes on student achievement among several clusters of strategies analyzed in another comprehensive meta-analysis (Schroeder et al., 2007). Thus, a collaboratively-designed study guide may have a greater impact on student learning compared to collaborative learning alone.

\section{Student Groups Collaborate to Construct Study Guide Questions}

One approach for collaborative study guide construction is to create one document where all students have the opportunity to add and edit information (Long, 2019). However, an instructor may desire to encourage the development of skills needed to collaborate in small groups rather than the class at large. The method described here required students to work in small groups to construct essay-style recall-based exam questions that were designed to assess one or more of the given chapter or unit objectives. The products of the collaborative activities were collected by the instructor; a selection of the student-designed questions was then compiled into a study guide that all students could use to prepare for the exams.

At the beginning of the semester, students were assigned by the instructor to collaborative working groups of three to four students in each group. Student-selected groups could possibly work here as well; however, instructor-assigned groups could balance groups in terms of GPA, previous knowledge on the topic, major, internship/work experiences, etc.

For each assigned collaborative activity, students were given approximately 12-15 minutes of class time. These collaborative activities were conducted nearly once per week (thirteen activities, one for each chapter of material) in a class that met biweekly. Each collaborative activity was worth less than $2 \%$ of the overall course grade. Students were not graded on the quality of the work produced in the collaborative activities; rather, students were graded on their preparation for (approximately 50\%) and participation (approximately 50\%) in the collaborative activities. Students prepared for the collaborative activity in a type of "flipped classroom" exercise. Individual students read the assigned chapter and completed a fill-in-the-blank quiz on Canvas, the university's learning management system. The students were able to view their scores and incorrect responses and were able to take the quiz as many times as possible in order to earn full credit. The quiz locked at the beginning of class on the day of the assigned activity.

Journal of the Scholarship of Teaching and Learning, Vol. 21, No. 3, October 2021. josotl.indiana.edu 
In class, collaborative groups were tasked with working together to create one study guide question and answer. These questions were intended to generate brief essay-style answers (e.g., approximately three to four sentences) that assessed the outcomes for one or more chapter objectives. During the collaboration, the instructor was available to answer questions and assessed the individual participation of each member of the group. The student-created questions and answers were collected by the instructor immediately after each collaborative activity. From all submitted questions (one per group, approximately 8-10 groups per class), the instructor chose three to four questions from each chapter activity (editing the selections for grammatical or other wording errors, if necessary) and compiled the chosen questions into an exam study guide distributed to the class. Answers were not provided with the study guide questions. As an incentive, each group could earn up to one bonus point per activity if their group's question was chosen for inclusion on the study guide. The study guide was updated approximately 24 hours after the activity, so students had access to and could use the study guide as much as possible before the exam. Although the study guides were designed to prepare students for exams, students were encouraged to use the study guides for preparation for all content-based assessments (e.g., quizzes and exams). One study guide question per chapter was selected by the instructor and used word-for-word on the exam.

\section{Implementation and Further Investigation}

Anecdotally, the vast majority of students in sections utilizing this technique developed good working relationships with their collaborative groups and appeared to be adequately prepared for exams. As participation was easily monitored by the instructor and was worth a portion of the grade, rarely did students fail to or inadequately participate. Students had the opportunity to confidentially report to the instructor if they felt group members were participating in the collaborative exercises unequally. Students that were unable to be physically present in class (e.g., due to illness) had the option to participate virtually using video or teleconferencing options if the group approved.

Although this technique was developed for a face-to-face course, the activities could be adapted to an online environment using synchronous meetings of student groups, asynchronous discussion boards, or through the use of other collaborative tools. If an instructor desires to incorporate any collaborative exercises into any mode of instruction, it is critical that the instructor clearly communicates the goals of the exercises and support students during the process (Bailey et al., 2015).

If the effectiveness of this collaborative technique is evaluated, students should be surveyed to determine the actual usage of the study guides as pedagogical aids. This would more clearly delineate whether it is the construction of the in-class activities or the usage of the study guides (or both) that could contribute to positive student outcomes. Additionally, it is possible that the depth of involvement in the collaborative exercises (Tsay \& Brady, 2012) and/or the type of dialogues (Chi \& Menekse, 2015) conducted in each group could contribute to differences in learning outcomes between students. Investigations into this method should investigate how the quality of the collaboration impacts student outcomes. Any future work in this area will contribute to an enhanced understanding of the efficacy of study guides and collaborations in student learning.

\section{Acknowledgments}

This study was supported by a Center for Innovation and Scholarship in Teaching and Learning (CISTL) Teaching Fellowship at Indiana University Northwest. The author also thanks Dr. Mary Ann Fischer for her valuable feedback on a draft of this submission.

Journal of the Scholarship of Teaching and Learning, Vol. 21, No. 3, October 2021. josotl.indiana.edu 


\section{References}

Bailey, S., Barber, L. K., \& Ferguson, A. J. (2015). Promoting perceived benefits of group projects: The role of instructor contributions and intragroup processes. Teaching of Psychology, 42(2), 179-183. https://doi.org/10.1177/0098628315573147

Chi, M. T. H., \& Menekse, M. (2015). Dialogue patterns in peer collaboration that promote learning. In Socializing Intelligence Through Academic Talk and Dialogue (pp. 253-264). Washington, DC: American Educational Research Association.

Chi, M. T. H., \& Wylie, R. (2014). The ICAP framework: Linking cognitive engagement to active learning outcomes. Educational Psychologist, 49(4), 219-243. https://doi.org/10.1080/00461520.2014.965823

Cushen, P. J., Hackathorn, J., Vázquez Brown, M. D., Rife, S. C., Joyce, A. W., Smith, E. D., Bordieri, M. J., Anderson, P. W., Karlsson, M. E., \& Daniels, J. (2019). 'What's on the test?": The impact of giving students a concept-list study guide. Teaching of Psychology, 46(2), 109-114. https://doi.org/10.1177/0098628319834171

Delucchi, M. (2007). Assessing the impact of group projects on examination performance in social statistics. Teaching in Higher Education, 12(4), 447-460. https://doi.org/10.1080/13562510701415383

Dickson, K. L., Devoley, M. S., \& Miller, M. D. (2006). Effect of study guide exercises on multiplechoice exam performance in introductory psychology. Teaching of Psychology, 33(1), 40-42. https://doi.org/10.1207\%2Fs15328023top3301_9

Dickson, K. L., Miller, M. D., \& Devoley, M. S. (2005). Effect of textbook study guides on student performance in introductory psychology. Teaching of Psychology, 32(1), 34-39. https://doi.org/10.1207/s15328023top3201_8

Drouin, M. A. (2010). Group-based formative summative assessment relates to improved student performance and satisfaction. Teaching of Psychology, 37(2), 114-118. https://doi.org/10.1080/00986281003626706

Gokhale, A. A. (2012). Collaborative learning and critical thinking. In N. M. Seel (Ed.), Encyclopedia of the Sciences of Learning (pp. 634-636). Springer US. https://doi.org/10.1007/978-1-44191428-6_910

Gurung, R. A. R. (2003). Pedagogical aids and student performance. Teaching of Psychology, 30(2), 9295. https://doi.org/10.1207/S15328023TOP3002_01

Gurung, R. A. R. (2004). Pedagogical aids: Learning enhancers or dangerous detours? Teaching of Psychology, 31(3), 164-166. https://doi.org/10.1207/s15328023top3103_1

Lloyd, M. E., \& Eastman, E. M. (1977). Performance on study-guide and non-study-guide test questions as a function of study guide availability. Journal of Personalized Instruction, 2(2), 80-83.

Long, R. (2019). Student-directed exam reviews, real-time collaborative composition, and assessment of student preparation. Journal of the Scholarship of Teaching and Learning, 19(3), 119-121. https://doi.org/10.14434/josotl.v19i2.23931

Mooney, G., Bligh, J. G., Leinster, S. J., \& Warenius, H. M. (1995). An electronic study guide for problem-based learning. Medical Education, 29(6), 397-402. https://doi.org/10.1111/j.13652923.1995.tb02860.x

Perkins, D. V., \& Saris, R. N. (2001). A “jigsaw classroom” technique for undergraduate statistics courses. Teaching of Psychology, 28(2), 111-113. https://doi.org/10.1207/S15328023TOP2802_09

Petrunich-Rutherford, M. L., \& Daniel, F. (2019). Collaborative quizzes: Impact on student performance and attendance. Teaching of Psychology, 46(2), 115-120. https://doi.org/10.1177/0098628319834172

Journal of the Scholarship of Teaching and Learning, Vol. 21, No. 3, October 2021. josotl.indiana.edu 
Polson, D. A. D. (1995). Fostering multiple repertoires in undergraduate behavior analysis students. The Behavior Analyst, 18(2), 293-299. https://doi.org/10.1007/BF03392716

Prince, M. (2004). Does active learning work? A review of the research. Journal of Engineering Education, 93(3), 223-231. https://doi.org/10.1002/j.2168-9830.2004.tb00809.x

Schroeder, C. M., Scott, T. P., Tolson, H., Huang, T.-Y., \& Lee, Y.-H. (2007). A meta-analysis of national research: Effects of teaching strategies on student achievement in science in the United States. Journal of Research in Science Teaching, 44(10), 1436-1460. https://doi.org/10.1002/tea.20212

Smith, M. E., Hinckley, C. C., \& Volk, G. L. (1991). Cooperative learning in the undergraduate laboratory. Journal of Chemical Education, 68(5), 413-415. https://doi.org/10.1021/ed068p413

Springer, L., Stanne, M. E., \& Donovan, S. S. (1999). Effects of small-group learning on undergraduates in science, mathematics, engineering, and technology: A meta-analysis. Review of Educational Research, 69(1), 21-51. https://doi.org/10.3102/00346543069001021

Tsay, M., \& Brady, M. (2012). A case study of cooperative learning and communication pedagogy: Does working in teams make a difference? Journal of the Scholarship of Teaching and Learning, 10, 78-89.

Wood, K. D. (1989). The study guide: A strategy review. Educational Resources Information Center. https:/ / eric.ed.gov/?id=ED322472

Wood, K. D., Lapp, D., \& Flood, J. (1992). Guiding readers through text: A review of study guides. Newark, DE: International Reading Association. 